\title{
Inter- and Intra-hierarchical Verbal Relatedness ${ }^{1}$
}

\author{
Bertram E. Garskof, John P. Houston, and Nathaniel J. Ehrlich \\ University of Michigan, Ann Arbor, Michigan
}

A segment of the current literature on verbal behavior has been concerned with the prediction of a number of dependent variables from knowledge of the relatedness of verbal units. Two techniques often employed in the measurement of verbal relatedness may be characterized as the conventional word-association approach (Jenkins, Mink and Russell, 1958; Russell and Jenkins, 1954; Russell and Storms, 1955) and the measurement of associative overlap (Bousfield, Whitmarsh, and Berkowitz, 1960; Deese, 1962; Garskof and Houston, 1963).

Few, if any, explicit statements have been made concerning the possible relationships existing between the nature of what is measured by the overlap technique and what is measured by the conventional word-association technique. The present authors maintain that these procedures measure two distinct and fundamentally different kinds of associative relatedness. If we define the associative meaning of a verbal unit as the associations connected to that unit (Deese, 1962; Garskof and Houston, 1963; Noble, 1952), then a pair of verbal units may be related in that they possess common associates and thus have a degree of shared meaning or by virtue of one unit being an associate or partial meaning of the other. We shall call the first type Interhierarchical Relatedness and the second, Intra-hierarchical Relatedness. If it can be shown, as the present experiments attempt to

1 This investigation was carried out during the tenures of the authors' Predoctoral Fellowships from the National Institute of Mental Health, United States Public Health Service. do, that each type of relatedness will influence verbal behavior when the effect of the other is partialled out, then we can conclude that there is some evidence for the correctness of our assertion of their distinctness.

Two experiments involving intentional learning and immediate recall were conducted. In both experiments the effects of Inter- and Intra-hierarchical Relatedness were observed independently. The dependent variable in Experiment I was clustering in recall and in Experiment II, amount of recall.

\section{EXPERIMENT I}

It has been demonstrated (Bousfield, Whitmarsh, and Berkowitz, 1960; Jenkins, Mink, and Russell, 1958) that both Inter- and Intrahierarchical Relatedness affect clustering in recall. In each of these studies no attempt was made to control the type of verbal relatedness not under investigation. The present experiment was designed to investigate, independently, the effects of the two kinds of relatedness on clustering. It was hypothesized that clustering of pairs of words in recall would vary directly with the strength of associative overlap when the effects of conventional word association were partialled out and that clustering would be a function of the strength of conventional association when the effects of associative overlap were partialled out.

\section{Method}

Subjecis. The $S$ s were 290 paid University of Michigan undergraduates enrolled in an intermediate level psychology course. 
Stimulus List. A list of 24 stimulus words (see Table 1) was composed of 12 pairs of nouns which were varied systematically in terms of Intra- and Inter-hierarchical Relatedness. The members of each of the 12 pairs were separated by at least two other stimulus words in the stimulus set.

Determination of Intra-hierarchical Relatedness. The Intra-hierarchical Relatedness values of each of the stimulus pairs were determined through the use of a conventional word-association task. Forty-five of the $S$ s, randomly chosen, were given lists of 24 nouns and asked to respond to each of these words with their first associates. Twelve of these 24 nouns were the first members of the 12 stimulus pairs (the remaining 12 words were employed in other experimentation and do not concern us here). Another group of $45 \mathrm{~S}$ s associated to another group of 24 nouns. Twelve of these 24 words were the second members of the 12 stimulus pairs (the remaining 12 words were employed in other experimentation).

Order of recall is not considered in the present experiment. Either member of a given A-B pair may be recalled first and serve as a stimulus for the second member of that pair. To consider the intra-hierarchical strength of a given pair as the one-way $A \rightarrow B$ strength would be inappropriate in the case where $B$ is recalled first and serves as a stimulus for the response $A$. Thus the means of the $A \rightarrow B$ and the $\mathrm{B} \rightarrow \mathrm{A}$ frequencies were used as the Intra-hierarchical Relatedness values for the 12 pairs. These means ranged from 0 to 19.5 and are presented in Table 1 in the form of percentages.

Determination of Inter-hierarchical Relatedness. The Inter-hierarchical Relatedness values of the 12 pairs were determined by a method used by Garskof and Houston (1963). According to their measure, termed the Relatedness Coefficient ( $R C$ ), the Interhierarchical Relatedness between two words is expressed as the ratio of the sum of the cross products of the ranks of the common hierarchical elements to the sum of the squares of the ranks of the larger hierarchy. A full account of the $\mathrm{RC}$ measure is given in the earlier paper. The Inter-hierarchical Relatedness or $\mathrm{RC}$ values of the 12 experimental pairs were computed in connection with the experiments reported in that paper. They ranged from .002 to .467 (the range of possible $\mathrm{RC}$ values is .0 to 1.0 ).

Although it would have been feasible to employ the group-frequency method (Cofer, 1957; Deese, 1962) in computing Inter-hierarchical Relatedness the individual rank method was chosen because there is some evidence which suggests that the latter is more sensitive to small amounts of associative overlap (Garskof and Houston, 1963).

Filler items. Six nouns composed the first and last three items in the stimulus list, bringing the stimulus list to 30 words. These filler items were introduced to reduce primacy and recency effects. They were not considered in the results.

Procedure. The remaining $200 \mathrm{Ss}$ were administered the recall task in a group. The $E$ informed the $S$ s that he was going to read a long list of words and that their task would be to recall as many of these words as they could immediately following the list presentation. The $S$ s were provided with paper and pencil and instructed to record the words in the order they came to mind. The $E$ read the 30 -word list at the rate of 1 word every $3 \mathrm{sec}$ as timed by a metronome. The $S \mathrm{~s}$ were given $5 \mathrm{~min}$ for recall.

\section{Results}

Post-experimental inquiry revealed that none of the $S$ s perceived the intent of the experiment. The number of times each of the 12 pairs was clustered was tabulated. Clustering was defined as the occurrence of the members of a pair next to each other on a recall sheet regardless of the order in which the members of the pair appeared.

Before the relationships between clustering and the two independent variables could be assessed it was necessary to determine whether the recallability of the pairs, irrespective of the associative relationships existing between their members, correlated with the obtained number of clusters. Differences in clustering may have been due to differences in recallability rather than to differences in the two independent variables. To do this recall scores for all pairs were computed and correlated with the number of clusters in the following manner. The number of times each member of each pair was recalled either alone or as the first member of a cluster was tabulated. These values were then summed over both members of every pair and are included in Table 1 as Recall Values. They do not include the number of times each word appeared as the second member of a cluster as these instances reflect, not the general recallability of the pairs, but rather the tendency for one member of a pair to call to mind the other as a function of the overlap or associa- 
TABLE 1

Experimental Pairs and Their Recall, RC, Word Association and Clustering Values

\begin{tabular}{lcccc}
\hline & & & & \multicolumn{2}{c}{$\begin{array}{c}\text { Per cent } \\
\text { word } \\
\text { Word pairs }\end{array}$} & $\begin{array}{c}\text { Recall } \\
\text { values }\end{array}$ & $\begin{array}{c}\text { Number of } \\
\text { clusters }\end{array}$ & $\begin{array}{c}\text { RC } \\
\text { association } \\
\text { strength }\end{array}$ \\
\hline Lizard-Reptile & 240 & 67 & .368 & 9 \\
Egg-Yolk & 200 & 60 & .467 & 43 \\
House-Home & 258 & 34 & .375 & 38 \\
Boat-Vessel & 207 & 22 & .224 & 9 \\
Restaurant-Food & 263 & 18 & .250 & 24 \\
Lunatic-Fool & 214 & 15 & .097 & 0 \\
Bandit-Thief & 201 & 14 & .300 & 10 \\
Emblem-Label & 219 & 9 & .037 & 1 \\
King-Governor & 237 & 6 & .002 & 1 \\
Ash-Gin & 216 & 5 & .184 & 0 \\
Night-Shadow & 262 & 3 & .012 & 1 \\
Bacon-Lip & 250 & 3 & & 0 \\
\hline
\end{tabular}

tive strength relationship existing between them. (The Recall Values plus twice the Number of Clusters for any given pair is the total number of times the members of that pair were recalled.) The correlation between the Recall Values and the Number of Clusters was non-significant $(r=.24)$. This result allows us to dismiss the effects of item recallability.

The correlation between the $\mathrm{RC}$ values and the Number of Clusters, with the conventional associative strengths of the pairs partialled out, was .68 $(p<.01)$. The correlation between clustering and conventional associative values with the effect of RC partialled out was $-.12(p>.05)$.

\section{EXPERIMENT II}

The results of Experiment I indicate that Intra-hierarchical Relatedness may not influence recall. It is possible that this finding may have been due to the nature of the task. The present experiment was designed to explore the effects of the two types of relatedness on the immediate recall of paired-associates which is closer to the basic S-R association paradigm than clustering in multiple-input free recall. It seemed reasonable to hypothesize that a positive intra-hierarchical effect might be obtained in this situation when the effects of Inter-hierarchical Relatedness were partialled out. It was also hypothesized that the inter-hierarchical effect would continue to be apparent when the effects of intra-hierarchical strength were partialled out. In the present experiment $S$ s were read a list of pairs of words which varied in terms of the two kinds of relatedness and then were asked to recall the second members of the pairs when presented with the first.

\section{Method}

Subjects. The Ss were 30 paid University of Michigan undergraduates enrolled in an intermediate level psychology course.

Word Pairs. The 20 word pairs employed in the study (see Table 2) varied systematically in terms of both Inter- and Intra-hierarchical Relatedness. For each A-B pair the intra-hierarchical strength was the per cent of the subjects in the association norms who gave $B$ as an associate to $A$. This method of determining Intra-hierarchical Re'atedness values was adopted because the recall task employed in this experiment was unidirectional. The inter-hierarchical values of 15 of the pairs were computed in connection with the Garskof and Houston experiment (1963). The remaining 5 were based upon data gathered in connection with an atlas of $2500 \mathrm{RC}$ values now in preparation by the authors.

The order of presentation was random, with rearrangements being made when placements were obviously inappropriate. The recall list was a dif- 
ferent random order of the first members of the pairs.

Since it has been shown that word frequency influences recall (Hall, 1954), it was necessary to show that no systematic relationship existed between the frequency of occurrences of the response members of the experimental pairs and the inter- or intrahierarchical levels of the pairs. To test this, correlations between frequency of occurrence (Thorndike and Lorge, 1944) and Inter-hierarchical Relatedness and frequency of occurrence and Intra-hierarchical Relatedness were obtained. These correlations were non-significant (.09 and .12 respectively).

Filler Items. Six pairs of nouns composed the first and last three items in the stimulus list, bringing the length of the list to 26 . These filler items were introduced to reduce recency and primacy effects. They were not considered in the results.

Procedure. The $30 \mathrm{Ss}$, meeting as a group, were informed that they would be read a list of pairs of words and that their task would be to recall the second members of these pairs when presented with the first members immediately following the list presentation. The $E$ read the words at the rate of 1 pair every $3 \mathrm{sec}$ as timed by a metronome. Following the list presentation $E$ read the first members of the pairs at the rate of 1 every $3 \mathrm{sec}$ and $S \mathrm{~s}$ recorded their responses on sheets of paper provided by $E$.

\section{Results}

The recall value of each pair was the number of times the group recalled the second member of the pair when given the first member. These recall values ranged from 7 to 30 . The recall values were correlated .46 $(p<$ .05) with the Relatedness Coefficient values when the conventional associative values were partialled out. The correlation between conventional associative strength and recall, with the effects of the Relatedness Coefficient partialled out, was .47 $(p<.05)$.

TABle 2

Experimental Pairs and Thetr RC, Word Association and Recall Values

\begin{tabular}{|c|c|c|c|}
\hline Word pairs & $\begin{array}{l}\text { Recall } \\
\text { values }\end{array}$ & $\begin{array}{c}\mathrm{RC} \\
\text { values }\end{array}$ & $\begin{array}{l}\text { Per cent } \\
\text { word } \\
\text { association } \\
\text { strength }\end{array}$ \\
\hline Sing-Song & 30 & .425 & $60^{*}$ \\
\hline Yolk-Egg & 26 & .467 & 80 \\
\hline House-Home & 26 & .375 & 47 \\
\hline Lunatic-Fool & 26 & .097 & 0 \\
\hline Scissors-Cut & 26 & .281 & $67 * *$ \\
\hline Glue-_Stick & 26 & .160 & $70 *$ \\
\hline Ocean-Sea & 24 & .498 & 24 \\
\hline Lizard-Reptile & 24 & .368 & 9 \\
\hline Swift_-Fast & 24 & .338 & 37 \\
\hline Bandit-Thief & 23 & .300 & $20^{* *}$ \\
\hline Restaurant-Food & 20 & .250 & 47 \\
\hline Vessel-Boat & 19 & .224 & 18 \\
\hline King-Governor & 16 & .037 & 0 \\
\hline Soldier-Army & 15 & .360 & $18 * *$ \\
\hline Shadow-Night & 15 & .184 & 2 \\
\hline Path-Street & 13 & .091 & 2 \\
\hline Dawn-Morning & 13 & .279 & 18 \\
\hline Midnight-Dark & 12 & .217 & 20 \\
\hline Storehouse-Closet & 8 & .019 & 2 \\
\hline Whisker-Prize & 7 & .005 & 0 \\
\hline
\end{tabular}

* Word association strength determined from Deese (1962, mimeo.).

** Word association strength determined from Russell and Jenkins (1954) norms. 


\section{Discussion}

The present studies give strong support to the proposal of the importance of inter-hierarchical associative strength in the determination of retention and clustering when intrahierarchical strength is controlled. It was expected that intra-hierarchical strength would also affect both clustering and retention. The evidence indicates that this variable did not influence clustering but that it did have an effect in the determination of retention in the paired-associate recall paradigm. This difference is understandable in view of the nature of the two tasks. The paired-associate task employed in Experiment II is closer to an S-R association paradigm than the clustering task. It is reasonable to infer that a basic S-R measure such as intra-hierarchical associative strength would have a greater effect in the second experiment.

However, the effect of conventional associative strength was less than might be expected from the results of other experiments in the association literature. For example, amount of conventional associative strength predicted amount of clustering (Jenkins, Mink, and Russell, 1958) and mediated generalization (Buzzota, 1956). The results of the present experiments, by giving support to a theory of the independent operation of two kinds of associative relationships, make it difficult to interpret these and other experiments which were based upon only one kind of associative strength without consideration for the influence of the other. Further experimentation is needed to determine the relative effects of these two associative variables on the different tasks currently under investigation in studies of verbal behavior.

\section{Summary}

Two measurement techniques have been used to assess associative strength between words, conventional word association, and the associative overlap. The former is a measure of the relative importance of individual meaning responses in their associative hierarchies and the latter measures similarity in the distribution of partial meaning responses. We have called these two kinds of associative strength Intra-hierarchical Relatedness and Inter-hierarchical Relatedness, respectively. A clustering and a retention experiment were performed to determine if these two kinds of associative strengths operate independently. The results indicate that, dependent upon the nature of the task, both may independently influence verbal behavior.

\section{REFERENCES}

Bousfield, W. A., Whitmarsh, G. A., and BerkowIrz, H. Partial response identities in associative clustering. J. gen. Psychol., 1960, 63, 233-238.

Buzzota, V. R. Association probability in the study of verbal behavior. Unpublished doctoral dissertation, Washington Univer., 1956.

Cofer, C. N. Associative commonality and rated similarity of certain words from Haagen's list. Psychol. Rep., 1957, 3, 603-606.

DeEse, J. On the structure of associative meaning. Psychol. Rev., 1962, 69, 161-175.

Garskof, B. E., and Houston, J. P. The measurement of verbal relatedness: An idiographic approach. Psychol. Rev., 1963, 70, 277-288.

HaLl, J. F. Learning as a function of word frequency. Amer. J. Psychol., 1954, 67, 138-140.

Jenkins, J. J., Mrnk, W. D., ANd Russeld, W. A. Associative clustering as a function of verbal association strength. Psychol. Rep., 1958, 4, 127136.

Noble, C. E. An analysis of meaning. Psychol. Rev., $1952,59,421-430$.

Russeld, W. A., AND Jenkins, J. J. Language in Behavior: The complete Minnesota norms for responses to 100 words from the Kent-Rosanoff Word Association Test. Tech. Rep. No: 11, N8onr 66216, Univer. of Minnesota, 1954.

Russelr, W. A., AND STORMs, L. H. Implicit verbal chaining in paired associate learning. $J$. exp. Psychol., 1955, 49, 287-293.

Thorndike, E. L., AND LoRge, I. The Teacher's word book of 30,000 words. New York: Bureau of Publications, Teachers College, Columbia Univer., 1944.

(Received November 9, 1962) 